\title{
MULTIKULTURALISASI PENDIDIKAN ISLAM SEJAK DINI DI ERA DIGITAL
}

\author{
Mufiqur Rahman \\ Institut Agama Islam (IAI) Al-Khairat Pamekasan \\ Muwafiq17@yahoo.com
}

\begin{abstract}
The failure to response digitalization evidenzed by the violence of child in the education institution and social environment that KPAI declared as the impact of digital culture and civilization that indicated instead of the failure of home's education. This paper will discuss and share an idea with literature view methode with the urgent of multicultural Islamic education. The Values of Multiculturalsm can be tought early like humanity, tolerance, respecting minority, loving a weak, keeping unity and peace, mentaining the culture. Those values can be implemented by the following methode such as; 1 . Al-awamiru wa an-nawahy (order and forbid). 2. Taqdimu al-qudwah al-toyyibah (modelling). 3. Al-tsawabu wa al-I'qobu (reward and punishment). 4. Al-Iyha'u (direct method). 5. Metode qisshoh (story).
\end{abstract}

Keywords : Multiculturalism, Islamic education, Digitalization

\begin{abstract}
Abstrak
Kegagalan merespon era digital dengan ditandai terjadinya kekerasan anak dalam institusi Pendidikan dan di lingkungan masyarakat yang disebut KPAI sebagai akibat dari budaya digital, mengindikasikan gagalnya Pendidikan keluarga. Artikel ini akan mendiskusikan dan menawarkan gagasan secara sederhana dengan metode pustaka akan pentingnya pendidikan islam dengan pendekatan multikultural. Nilai-nilai multikultural yang dapat diajarkan kepada anak sejak dini adalah seperti humanis, toleransi, menghargai, menerima, mengutamakan silaturahim, (dialog) pada semua individu, menyayangi kaum lemah, dan monoritas, menjaga persatuan, dan perdamaian, mengembangkan budaya, menjaga kearifan budaya lokal dalam masyarakat. Berbagai macam metode pendidikan anak sejak dini dalam Pendidikan Islam, di antaranya adalah: 1. Al-awamiru wa an-Nawahy (perintah dan larangan). 2. Taqdimu al-Qudwah altoyyibah (Pendidikan keteladanan). 3. Al-Tsawabu wa al-I'qobu (reward and punishment). 4. Al-Iyha'u (direct method) atau metode langsung. 5. Metode Qisshoh ( bercerita).
\end{abstract}

Kata kunci :Multikulturasi, Pendidikan Agama Islam, Digital 


\section{Pendahuluan}

Dunia pendidikan tercoreng dengan kasus kekerasan terhadap guru di Sampang Madura. Dengan headline selamatkan guru budi, seorang guru seni yang menjadi korban kekerasan siswanya yang akhirnya menghembuskan nafas terakhir. Guru budi menjadi sorotan publik dan mengisi berita nasional. Kekerasan yang dilakukan siswa terhadap guru adalah insiden buruk dalam dunia Pendidikan yang harus ditelaah dan dipelajari dalam segala aspek. Pendidikan yang diterima anak di rumah/keluarga dan era global yang serba digital.

Tesis penulis menanggapi kedua kasus di atas adalah di zaman globalisasi ini yang ditandai dengan pasifnya informasi yang dengan gampang diterima melalui digitalisasi sains dan informasi menyebabkan digitalisasi berubah menjadi subjek yang memberikan ilmu pengetahuan. Digital menjadi makhluk hidup yang dapat menjadi guru dan informan yang sangat gampang diterima oleh anak. Informasi dapat diterima melalui sosial media dan aplikasi online. Tidak menutup kemungkinan akan memberikan dampak manfaat dan dapat memberikan dampak negatif. Ketiga digital menjelma menjadi guru, maka dia akan diikuti atau ditinggalan. Kemampuan untuk mengambil sikap terhadap digitalisasai ini adalah Pendidikan anak sejak dini. Pendidikan yang mencetak karakter anak yang bernilai religius dan humanis. Dengan nilai-nilai multikultur yang toleran dan menghormati perbedaan.

Komisi perlindungan anak Indonesia (KPAI) mencatat selama 4 tahun terakhir kekerasan pada anak terus meningkat.Terakhir di tahun 2014 ada 5.006 kasus. Rata-rata penaikan kasus dimulai pada tahun 2011sebanyak 1000 kasus kekerasan pada anak.di antara kekerasan dalam keluarga, Lembaga Pendidikan, serta pornografi dan cyber crime. Khusus kekerasan pada anak yang dipicu oleh social media dan internet sebanyak 322 kasus di tahun 2014. Jumlah ini terus naik hingga 100 kasus. ${ }^{1} \mathrm{KPAI}$ menyatakan bahwa banyak kekerasan anak yang terjadi akibat anak tidak bisa bersikap positif terhadap social media, solusinya adalah memperkuat pengawasan guru, orangtua, dan pendidikan keluarga.

Hemat penulis menanggapi kasus ini memperkuat pendidikan keluarga dengan pendidikan multikultur, dengan mengajarkan nilai-nilai keagamanan, seperti kasih

\footnotetext{
${ }^{1}$ Maria Ulfa. Kekerasan pada anak dimulai dari internet, (http://m.suara.com/wawancara.) diakses 10 April 2018.
} 
sayang, menghormat dan menghargai melalui pembiasaan sejak dini. Multikulturasi adalah upaya untuk merevitalisasi pendidikan dengan dasar paham multikulturalisme. Multikulruralisme dalam Bahasa anak Eropa dan Afrika Amerika dikatakan sebagaimana berikut

“ It's time to start learning about things they told you,you didn't need to know...learning about me, instead of learning about them, starting to leran about her instead of learning about him. It's a connection that makes educations education." 2

Pernyataan anak-anak Eropa dan Afrika Amerika tersebut menindikasikan kesamaan pandangan (equal view) dalam Pendidikan, mereka harus menerima materi yang sama. Pernyataan itu membuat kita berfikir kembali bagaimana di dalam keberagaman sosial. Etnis dan budaya di kelas, terjadi komunikasi dan transformasi budaya dengan baik.Bahwa tidak ada prototipe dan intimidasi, bullying antar anak di sekolah. Tugas guru adalah bagaimana untuk mengkorporasi segala perbedaan anak di kelas ke dalam kurikulum yang dapat menyatukan suara mereka dan membuat perbedaan menjadi nilai yang tumbuh darinya toleransi dan saling menghargai. ${ }^{3}$

Multikulturasi Pendidikan sangat urgen di tengah arus globalisasi yang ditendai dengan perkembangan digitalisasi. Apalagi Indonesia adalah negara dengan jumlah populasi tertinggi sebagai negara plural, Indonesia memiliki 17.508 pulau.300 suku dengan 583 bahasa dan 6 agama (Islam, Hindu, Budha, Katolik, Protestan, dan Konghucu) kepercayaan dan berbagai tradisi keagamaan. Sebagaimana disebutkan Tolhah, bahwa realitas keberagaman yang tinggi ini jika tidak dimenage dengan baik akan dapat menimbulkan disintegrasi bangsa dan dapat menyebabkan negara gagal. Seperti Yugoslafia, Korea, Syiria, Afganistan, Yaman. ${ }^{4}$

Meski Indonesia memiliki keragaman etnik tetapi memiliki tujuan yang sama, yakni menuju masyarakat adil dan sejahtera. Karena itu, menjadi penting pengembangan pendidikan multikultural, dalam memberi peluang sama pada seluruh anak bangsa tanpa dalam perbedaan etnik, budaya dan agama, yang memberikan penghargaan terhadap keragaman, dan yang memberikan hak-hak sama bagi etnik minoritas, dalam upaya memperkuatpersatuan dan kesatuan, identitas nasional dan citra

\footnotetext{
${ }^{2}$ James A Bank \& Cherry A. McGee Banks, Multicultural education: Issues and Perspective ( United State of America, Willey, 2010), 159.

${ }^{3}$ Ibid, 159.

${ }^{4}$ Mohammad Tolhah Hasan, Multiculturalisation of Islamic education in Indonesia : an inevitability (international conference on Islam Nusantara, National integrity, and world peace, March, 27-28, 2018), 2
} 
bangsa di mata dunia internasional. Dalam hal ini, sekolah harus mendesain proses pembelajaran, mempersiapkan kurikulum, serta mempersiapkan guru yang memiliki persepsi, sikap dan perilaku multikultural, sehingga menjadi bagian yang memberikan kontribusi positif terhadap pembinaan sikap multikultural para siswanya. ${ }^{5}$ Sebagaimana disebut Tolhah bahwa solusinya adalah bagaimana memelihara toleransi, hamoni, dan menghormati yang lain dan kesiapan untuk hidup bersama secara harmonis antar kelompok dengan kompleksitas keberagaman budaya dan etnis, agama dst. kenyataan ini hanya dapat diatasi dengan pendidikan multikulturalisme atau multikulturasi pendidikan sejak dini. ${ }^{6}$

Multikulturasi pendidikan sejak dini adalah sebuah upaya memperkenalkan pendidikan yang menawarkan beberapa konten dan tujuan Pendidikan dengan pendekatan nilai mutltikultural sejak dini. Persoalan ini patut direspon dengan cepat secepat transformasi budaya dan pengetahuan yang sangat cepat (degitalisasi).Bagaimana kemudian pendidikan dapat juga diterima tanpa guru, atau siswa dapat belajar secara otodidak dengan memanfaatkan media digital seperti internet dan bentuk aplikasi pembelajaran lainnya.

Ketika pendidikan sudah mengalami kemajuan dengan kemajuan globalisasi atau degitalisasi.Maka sikap yang harus diambil menurut penulis adalah bagaimana menghadapi globalisasi atau degitalisasi. Kenyataan ini adalah sebuah keniscayaan yang harus dihadapi bukan malah lari dan meninggalkan digiltalisasi pendidikan. Era ini adalah era dimana multikulturasi pendidikan sangat diperlukan untuk membendung praktek-praktek bulliying, kekerasan Pendidikan, streotipe dan diskriminalisasi yang dilakukan secara digital.

\section{Multikulturasi Pendidikan Sejak Dini}

Multikulturasi Pendidikan seharusnya dilakukan sejak dini, back to family atau communication in the family merupakan sebuah pernyataan bagaimana di Amerika Serikat sebagai kampiun modernisasi sangat mementingkan peranan keluarga, mereka merasakan betapa sulitnya membangun keluarga yang harmonis, sejahtera (sakinah).

\footnotetext{
${ }^{5}$ Dede Rosyada, Pendidikan Multikultural Di Indonesia Sebuah Pandangan Konsepsional, (Sosio Didaktika: vol. 1, no. 1 mei 2014), 1.

${ }^{6}$ Mohammad Tolhah Hasan, Multiculturalisation of Islamic education..., 4
} 
Bahkan workshop parenting laris manis dilakukan peserta yang sangat banyak. Ini adalah bentuk bagaimana kemudian Pendidikan keluarga sangat berpengaruh dan dianggap awal dari pendidikan yang menawarkan pendekatan kasih sayang, harmonis, cinta damai dan keterbukaan. ${ }^{7}$ Kebiasan yang ada dalam keluarga dapat memicu anak untuk berkembang dan bersikap kemudian hari menjadi anak yang baik dan lembut. Dalam konteks keluarga sebagai fungsi edukatif, terjadi proses Pendidikan dan proses pembelajaran antar anggota keluarga. Dalam kondisi demikian orangtua menjadi pemegang peran utama dalam proses pembelajaran dan pendidikan anak-anaknya. Ini akan membantu perkembangan kepribadian anak dalam ranah kognisi, afektif dan skill. ${ }^{8}$

Multikulturasi pendidikan sejak dini dalam keluarga juga setidaknya dapat ditelaah beberapa dimensi pendidikan multikultural. Dalam konteks ini, Penulis akan menggunakan teori James a Bank untuk menelaah the dimension of multicultural education. James menyebutkan ada 5 dimensi Pendidikan multikultural harus ada dalam Pendidikan multikultural. Lima dimensi tersebut sebagaimana penjelasan berikut ini:

1. Content integration (Integrasi Pendidikan multicultural dalam kurikulum). Adalah bagaimana seorang pendidik dalam pembelajaran dapat membawa dan mengisi konten paedagogik dengan materi variety of culture keberagaman budaya.

2. The knowledge contruction process ( kontruksi ilmu pengetahuan), bagaimana seorang pendidik dapat membantu siswa memahami dan melakukan investigasi dan menentukan asumsi kultural, sumber atau sejarah kebudayaan, dan sudut pandang kultural, yang mempengaruhi kepada kontruksi pengetahuan siswa.

3. Prejudice reduction (pengurangan prasangka), dimensi ini berfokus kepada karakteristik siswa khususnya dalam prilakau rasis dan bagaimana focus ini dapat dimodifikasi dalam metode dan materi pembelajaran

4. An equity pedagogy (Pedagogik kesetaraan antar manusia), adalah bentuk kesetaraan antar manusia bagaimana guru dalam tujuan pencapaian pembelajaran dari siswa berlatar belakang perbedaan etnis dan ras, budaya, dan gender, dan kelompok sosial.

\footnotetext{
${ }^{7}$ Mohammad Tholhah Hasan, Pendidikan anak usia dini dalam keluarga (Jakarta: Mitra Abadi Press, 2009), 5

${ }^{8}$ Ibid, 9.
} 
Bagaimana tidak terjadi perbedaan ekonomi dan kelas social dalam menentukan pencapaian pembelajaran. ${ }^{9}$

5. An empowering School culture and social structure (pembedayaan budaya sekolah dan struktur sosial). adalah bentuk pengelompokan dan pelabelan dimana siswa di sekolah dapat berpartisipasi dalam kegiatan sekolah, seperti olahraga, dan adanya komunikasi yang bai kantar rasa tau etnis dari guru ke siswa yang harus teruji dengan baik. Sehingga dapat memperdayakan dan menguatkan hubungan antar ras, etnis, dan kelompok gender ${ }^{10}$

\section{Skema 01. Dimensi Pendidikan Multikultural James A. Bank}

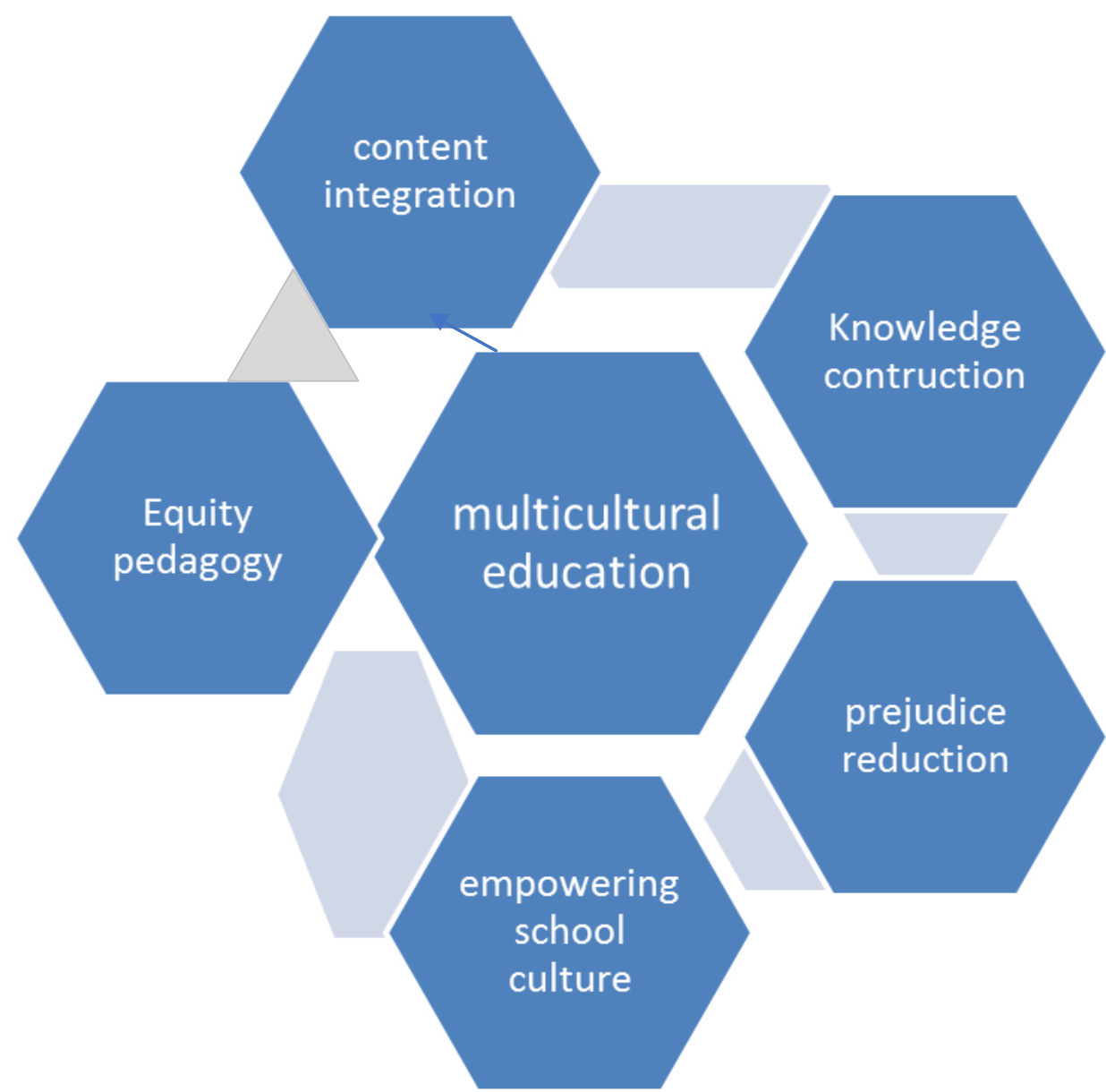

\footnotetext{
${ }^{9}$ H.A.R. Tilaar, Multikulturalisme : Tantangan-tantangan besar masa depan dalam tranformasi Pendidikan Nasional ( Jakarta : gramedia, 2004), 140.

${ }^{10}$ James A. Bank \& Cherry A. McGee Banks, Multicultural education : Issues and Perspective (United state of America : Willey, 2010), 22.
} 
Lima dimensi Pendidikan Multikultural ini dalam teori James A Bank adalah gagasan besar yang harus ada dalam implementasi atau internalisasi multikulturalisme. Menurut Romaine untuk mengimplemntasikan Pendidikan multikulturalisme di dalam keluarga atau di sekolah harus dibangun dengan kekuatan ikatan/hubungan (relationship), dan interaksi verbal antar guru/orang tua dan anak, kultur, kurikulum, dan kegiatan ektrakurikuler. Nilai-nilai multikultural harus dikontrol melalui normanorma sekolah atau keluarga sehingga dapat sistemik terkontruk dalam diri anak dan siswa. $^{11}$

Dalam kontek Pendidikan Islam, kontruksi atau habituasi nilai atau norma positif dapat dimulai sejak umur 7 tahun sesuai dengan nash hadish yang diriwayatkan oleh Abu dawud yang artinya "perintahkanlah anak-anakmu untuk melakukan sholah ketika mereka berumur 7 tahun dan pukullah mereka saat umur 10 tahun. ${ }^{12}$ Diterangkan oleh al-Qobisy bahwa tidak diperbolehkan anak dipukul karena sholat pada umur 7 tahun, karena sesungguhnya sejak umur 7 tahun itu menurut al-Qobisy anak sudah memulai mencari ilmu, namun sesungguhnya Orangtua dapat memulai pembiasaan anak, sejak mereka telah tamyiz dan mulai berakal. Sesuai yang dikatakan oleh Abu Bakar "walil qoumi fitta'lim sirotub badi'ah wa huwa anna ashoghir minhum idza aqola ba'athu ilal maktabi" dari sini menurt al-Qobisi tidak ada batasan dalam umur kapan mulainya anak menuntut ilmu bisa juga dimulai saat umur 5 sd 7. al-Qobisi pernah ditanyak oleh Malik tentang mengajarkan anak di masjid kemudian al-Qobisi menjawab saya tidak berpendapat bahwa ini boleh, karena anak-anak belum tahu menjaga najis. ${ }^{13}$ Dalam konteks ini menurut penulis bahwa saat umur 3 tahun pembiasaan sudah dapat diajarkan kepada anak, karena pembiasaan juga merupakan aspek dari pembentukan kepribadian anak. Pada umur itu anak-anak sudah dibiasakan untuk jujur, tidak boleh berbicara kasar dst.

Pendidikan adalah salah satu aspek terpenting dalam pengembangan manusia dan mungkin institusi sosial paling berpengaruh di masyarakat manapun. Secara umum, pendidikan adalah untuk mentransmisikan serangkaian keyakinan, nilai, norma, pemahaman dari generasi dewasa kepada genersi muda. Islam memandang pendidikan sebagai bentuk ibadah (ibadah) dimana umat Islam berbagi seperangkat nilai yang sama

\footnotetext{
${ }^{11}$ Ibid, 23.

${ }^{12}$ Ahmad Fu'ad al-Akhwani, at-Tarbiyah fi at-Ta'lim ( Mesir : Darul Ma'arif,1119), 59

${ }^{13}$ Ibid, 60
} 
berdasarkan Alquran (sumber fundamental dan paling andal untuk banyak bidang pengetahuan) dan Sunnah. Hassan menggambarkan Pendidikan dari perspektif Islam, sebagai proses lama mempersiapkan seseorang untuk mengaktualisasikan perannya sebagai khalifah Allah di bumi dengan demikian berkontribusi sepenuhnya pada rekonstruksi dan perkembangan masyarakatnya untuk mencapai kesejahteraan di dunia dan akhirat. Untuk mencapai kesepakatan mengenai tujuan pendidikan Islam, mungkin bermanfaat untuk memperoleh definisi pendidikan dan pendidikan Islam terlebih dahulu. Ashraf mendefinisikan pendidikan sebagai sebuah proses yang melibatkan tiga penghargaan: individu, masyarakat atau masyarakat tempat dia berada dan keseluruhan isi kenyataan, baik material maupun spiritual, yang memainkan peran dominan dalam menentukan sifat dan takdir. Manusia dan masyarakat. Oleh karena itu, pendidikan memainkan peran yang sangat penting dan merupakan pilar bagi pembangunan nasional di banyak masyarakat. Al-Attas mempertahankan bahwa tujuan pendidikan Islam bukan untuk menjelaskan kepala murid dengan fakta tapi juga mempersiapkannya untuk kehidupan yang suci dan ketulusan. Komitmen total untuk membangun karakter berdasarkan cita-cita etika Islam adalah tujuan tertinggi pendidikan Islam. Di sini ia menekankan pada bangunan karakter yang perlu dibentuk bersama dalam kurikulum pendidikan yang dianggapnya sebagai tujuan tertinggi pendidikan Islam. Definisi pendidikan Islam yang lebih komprehensif disusun pada Konferensi Dunia Pertama tentang Pendidikan Muslim di Makkah pada tahun 1977, dengan kata-kata berikut: ${ }^{14}$

Education should aim at the balanced growth of the total personality of man through the training of man's spirit, intellect, his rational self, feelings and bodily senses. Education should cater therefore for the growth of man in all its aspects: spiritual, intellectual, imaginative, physical, scientific, linguistic, both individually and collectively and motivate all aspects towards goodness and the attainment of perfection. The ultimate aim of Muslim education lies in the realization of complete submission to Allah on the level of the individual, the community and humanity at large.

Hasil kesepakatan dalam konferensi Makkah di atas menekankan bahwa Pendidikan harus mengarah pada pertumbuhan kepribadian manusia melalui pelatihan, kecerdasan, perasaan, rasio, perasaan indra dan fisik. Pendidikan harus diperuntukkan bagi pertumbuhan manusia dalam semua aspeknya: spiritual, intelektual, imajinatif,

\footnotetext{
${ }^{14}$ Che Noraini Hashim \& Hasan Langgulung, Islamic Religious Curriculum in Muslim Countries: The Experiences of Indonesia and Malaysia (Bulletin of Education \& Research June 2008, Vol. 30, No. 1, pp. 1-19), 1-2.
} 
fisik, ilmiah, linguistik, baik secara individu maupun kolektif dan memotivasi semua aspek menuju kebaikan dan pencapaian kesempurnaan. Tujuan utama pendidikan muslim terletak pada realisasi penyerahan sepenuhnya kepada Allah pada tingkat individu, masyarakat dan kemanusiaan pada umumnya.

Oleh karena itu, menurut Langgulung, Konferensi Mekkah itu sebagaimana disepakati oleh para ilmuwan Muslim dalam Deklarasi Mekkah di atas, jelas bahwa untuk mengembangkan Konsep dan masyarakat Islam, Konsep pendidikan dan kurikulumnya harus direncanakan menurut pandangan dunia Islam karena Langgulung menekankan bahwa islamisasi kurikulum adalah menempatkan kurikulum dan keempat komponennya yaitu tujuan dan sasaran, isi, metode pengajaran dan metode evaluasi dalam pandangan dunia Islam. ${ }^{15}$

\section{Nilai Multikulturasi Pendidikan Sejak Dini}

Nilai-nilai yang dapat diajarkan kepada anak sejak dini adalah nilai Pendidikan Islam Multikultural, yang dijelaskan oleh Gusdur dalam Mun'im menuturkan bahwa peradaban dunia ini dapat dilestarikan dan dikembangkan dengan baik jika terwujud nilai-nilai multicultural, seperti humanis, toleransi, menghargai, menerima, mengutamakan silaturahim, (dialog) pada semua individu, kelompok organisasi, dan lintas paham keyakinan, menyayangi kaum lemah, dan monoritas, menjaga persatuan, dan perdamaian, mengembangkan budaya, menjaga kearifan budaya lokal dalam masyarakat. ${ }^{16}$ Sedangkan M. Tholhah Hasan menjelaskan bahwa nilai-nilai yang harus ada dalam masyarakat adalah komitmen untuk bisa hidup bersama, saling menghormati, bekerjasama, tolong menolong, gotong royong dalam suasana hidup rukun dan damai. Tidak jauh berbeda juga pentinya Pendidikan nilai sejak dini juga diungkapkan oleh Nurcholis Madjid dan Amien Rais juga meyakini pentingnya Pendidikan nilai yang akan menjadi energi anak seperti nilai keberagaman (pluralism), nilai keadilan, nilai toleransi, nilai kemanusian, nilai penghargaan terhadap kepemilikan, nilai tanggung jawab dan nilai kebersamaan. ${ }^{17}$

\footnotetext{
${ }^{15}$ Ibid, 2.

${ }^{16}$ H.A.R. Tilaar, Multikulturalisme : Tantangan-tantangan besar masa depan dalam tranformasi Pendidikan Nasional ( Jakarta : gramedia, 2004), 91

${ }^{17}$ Mufiqur Rahman, Demokrasi dalam filsafat pendidikan barat dan Islam (kajian tentang nilai-nilai demokrasi dan implemntasinya denan konteks Pendidikan Indonesia, ( Cendekia : Vol 3. No. 2. Desember 2017), 21
} 
Tabel 01.

Tabel Nilai Pendidikan Islam Multikultural madzhab Gusdur dan Tolchah Hasan

\begin{tabular}{cc}
\hline K.H. Abdurrahman Wahid (Gusdur) & Mohammad Tolchah Hasan \\
\hline Humanis & Kometmen untuk bisa hidup bersama \\
Toleransi & Saling hormati \\
Menghargai & Bekerjasama \\
Menerima & Tolong menolong \\
Mengutamakan silaturrahim & Gotong royong \\
Dialog lintas kelompok keagama & Hidup rukun dan damai \\
An & \\
Menyayangi yang lemah dan minoritas & \\
Menjaga Persatuan & \\
Menjaga kearifan local dalam & \\
masyarakat & \\
\hline
\end{tabular}

\section{Metode Transformasi Nilai Multikulturasi Pendidikan sejak dini}

Metode dalam bahasa arab disebut Al-thoriqat yang memiliki arti jalan atau cara yang harus ditempuh. Pengertian metode dalam Pendidikan adalah cara yang ditempuh untuk sampai pada tujuan pendidikan yang sudah ditetapkan. Dalam konteks Islam alSyaibani dalam Haris menyebutkan ada empat yang menjadi dasar pertimbangan penggunaan metode Pendidikan Islam, yaitu ; dasar agama, biologis, pskilogis dan dasar sosiologis, karena itu menurut Al-Syaibani metode pendidikan merangkum empat tujuan pokok. Pertama, menolong anak didik untuk mengembangkan kemampuan individu, kedua.membiasakan anak didik membentuk sikap diri, ketiga, membantu anak didik bertindak efektif, dan yang keempat adalah membimbing aktivitas anak didik. AlSyaibani menyimpulkan bahwa metode Pendidikan untuk anak sangat fleksibel dan menyesuaikan dengan kebutuhan anak. ${ }^{18}$

\footnotetext{
${ }^{18}$ Abd. Haris, Pendidikan karakter berbasis Tauhid, sebuah pendekatan filosofis (Sidoarjo: Afkarpress, 2012), 28.
} 
Berbagai macam metode pendidikan anak sejak dini dalam pendidikan Islam, di antaranya adalah : 1. Al-awamiru wa an-nawahy (perintah dan larangan), yaitu perintah orangtua terhadap anaknya kepada pekerjaan yang wajib dilakukan oleh anak, seperti perintah Sholat dan larangan untuk meninggalkannya. 2. Taqdimu al-qudwah altoyyibah (Pendidikan keteladanan), Pendidikan Islam sangat memperhatikan keteladanan dan melatakkannya pada metode yang sangat penting dalam Pendidikan. Maka anak dalam Pendidikan akan mengikuti keteladanan orangtua, guru, dan lingkungan. Maka orangtua harus memberikan contoh yang baik dalam setiap perkataannya dan perbuatannya. 3. Al-Tsawabu wa al-I'qobu (reward and punishment) reward orangtua terhadap anaknya akan menjadikan diri anak semakin berdaya dan reward ini akan memuaskan kehendak dan cita anak, sehingga anak merasa dirinya berhasil dan dihargai dan akan tumbuh jiwa yang positif. Sedangkan punishment akan diberikan orangtua kepada anak dalam kondisi yang darurat, punishment diberikan dengan cara yang berbeda disesuaikan dengan kondisi anak. Namun nasehat Imam alGazali dalam hal ini adalah hindari memberikan punishmen di dekat mata, dan sebisa mungkin tidak di depan anak-anak yang lain. Sebab, ini akan membuat anak sangat malu dan anak akan mendapatkan cacian dari teman-temannya. 4. Al-Iyha'u (direct method) atau metode langsung, ini sangat baik, seperti orangtua memberikan contoh sholat di depan anak, dengan maksud anak dapat menirunya. Seperti juga membaca alQuran. 5. Metode Qisshoh (bercerita) metode ini sangat baik untuk melatih perasan anak sehingga melatih anak untuk berimajinasi ${ }^{19}$

Metode yang dijelaskan di atas juga diterangkan oleh Haris bahwa metode Pendidikan sejak dini juga dapat dilakukan dengan keteladanan, pembiasaan, ibrar dan mau'izhah (Pendidikan dengan 'ibrar digunakan dalam mengajar aspek kehidupan, kejadian alam, perenungan akan keagungan Allah dalam mengajarkan mata pelajaran apapun sedangkan Mau'idhat adalah nasehat, petuah), metode perumpamaan (dapat memberikan kesan dan pengaruh edukatif kepada anak, dapat untuk menjeleaskan makna kongkrit, sebagaimana perumpamaan laba-laba yang membuat rumah Q.S. alAnkabut (29): 41), metode targhib dan tarhib (metode ini mengandung aspek imam, sedangkan metode hukuman dan ganjaran tidak mengandung dimensi iman. Metode ini

\footnotetext{
${ }^{19}$ Abdul Ghina A'bbud \& Hasan Ibrahim A'dul A'l, at-Tarbiyah al-Islamiyah wa tahaddiyat al-Asyr (Mesir: Darul fiqr al-A'roby, 1990), 468.
} 
lebih kuat pengaruhnya kepada anak), dan metode pendidikan hiwar percakapan yang terus menerus mengenai suatu topik yang dengan sengaja diarahkan kepada suatu topik yang dikehendaki guru, sehingga anak tertarik untuk mengetahui kesimpulannya. Apabila metode hiwar ini dilakukan dengan baik, memenuhi etika Islam, maka cara berdialog, sikap orang yang terlibat, akan mempengaruhi anak sehingga meninggalkan pengaruh akhlak yang baik, sikap, dalam pembicaraan menghargai pendapat orang lain. $^{20}$

\section{Menyiapkan Anak Melalui Pendidikan Islam Multikultural}

Analisis Alvin Toffler menjelelaskan bahwa era kemanusiaan dibagi menjadi tiga bagian, yaitu era masyarakat agraris, masyarakat industry, dan masyarakat informasi. ${ }^{21}$ Analisis Toffler hari telah menjadi kenyataan bahwa kita tidak bisa menghindari era informasi digital yang ditandai dengan perkembangan computer ke internet, kemudian perkembang ke telepon seluler dan situs jejaring sosial. ${ }^{22}$ Era digital ini tidak hanya menguasai bidang ekonomi politik, tapi juga menguasai dunia Pendidikan. Seperti yang disampaikan di pendahuluan makalah ini.Bahwa tidak sedikit yang menjadi korban kekerasan anak yang disampaikan oleh KPAI yang diakibatkan oleh abuse of digital salah menggunakan digital.Artinya anak kita masih ada yang belum siap membawa kemajuan ini kepada hal-hal yang positif, ini dikarenakan Pendidikan yang dialaminya tidak menjadikan mereka memiliki daya filter memilih mana yang baik dan buruk.

Penulis setuju dengan 7 manfaat era digital ; sumber informasi, membangun kreatifitas, komunikasi, pembelajaran jarak jauh, jejaring social, mendorong pertumbuhan usaha, memprbaiki pelayanan publik. ${ }^{23}$ Namun sebelum itu dihadapi oleh anak, mereka harus dibekali dengan Pendidikan Islam dengan pendekatan multikultur.

Ketika anak telah memiliki pengalaman yang baik, dengan pendidikan yang ditekankan sejak dini dalam keluarga, dengan nilai-nilai yang baik seperti nilai-nilai multikultural, humanis, toleransi, menghargai, menerima, mengutamakan silaturahim,

\footnotetext{
${ }^{20}$ Abd. Haris, Pendidikan karakter berbasis Tauhid, ... 30-40.

${ }^{21}$ AG. Eka Wenats Wuryanto, Digitalisasi masyarakat: Menilik kekuatan dan kelemahan dinamika era informasi digital dan masyarakat informasi, (Jurnal Ilmu Komunikasi, Vol. 1.no.2 Desember 131-142, 132.

${ }^{22}$ Kemendikbud, Mendidik anak di era digital, ( Jakarta: Kemendikbud, 2017), 3.

${ }^{23}$ Ibid, 8 .
} 
menyayangi kaum lemah, dan monoritas, menjaga persatuan, dan perdamaian, mengembangkan budaya, menjaga kearifan budaya lokal dalam masyarakat. Komitmen untuk bisa hidup bersama, saling menghormati, bekerjasama, tolong menolong, gotong royong dalam suasana hidup rukun dan damai. Sebagaimana anak-anak memiliki hak untuk mendapatkan Pendidikan yang baik, dan hak untuk tumbuh kembang kearah yang yang lebih baik. ${ }^{24}$

Terkontruk dan terinternalisasi dalam sikap (akhlak) anak sehingga menjadi kepribadian dan watak anak, maka anak-anak telah siap berhadapan dengan segala aspek kemajuan zaman termasuk globalisasi dan digitalisasi yang merupakan instrument atau alat. Relatifisme digital akan berbuah positif, sebab anak sudah berdaya dengan paragdigma yang positif. Mereka akan menggunakan kemajuan ini dengan sesuatu yang mendatangkan maslahat dan menjauhkan dirinya dari sesuatu yang mendatangkan mudhorat.

Anak "zaman now" adalah generasi digital yang identitasnya adalah Facebook, twitter, Path, Instragram, Youtube, untuk membuktikan bahwa mereka adalah anak yang ada untuk dunia, yang cendrung terbuka. ${ }^{25}$ Dengan menampilkan segala kebebasan ekspresi dan juga sebagai alat untuk belajar dari informasi yang cepat. Pada saat inilah anak-anak harus memiliki nilai yang kuat untuk menjatuh pilihan memutuskan dan melakukan filterisasi informasi yang kadang menciptakan perlakukan yang tidak semestinya.

Orangtua dan pendidikan di keluarga harus mencegah dan menjaga anak dari pandangan monokultur atau tumbuh dengan perkembangan social yang kurang baik yaitu lebih mementingkan diri sendiri sehingga sulit bergaul secara langsung. Sulit memahami nuansa perasaan, pasif karena sebagian besar anak terlambat bicara karena kurangnya latihan, mereka lebih banyak bermain sendiri, terlalu banyak menonton TV dengan tidak mengimbangi interaksi dengan dunia nyata. ${ }^{26}$ Menurut penulis, sikap ini akan terjadi karena dunia digital sudah mengguruinya. Apabila dunia digital menjadi guru anak, dan pada saat ini anak tidak memiliki Pendidikan agama yang baik, tidak menutup kemungkinan inilah yang sisebut KPAI sebagai salah satu penyebab maraknya

\footnotetext{
${ }^{24}$ Mufiqur Rahman, Menakar efektivitas Program aflatoun dalam Pendidikan karakter (Jurnal Pendidikan Agama Islam Volume 3 Nomor 2 November 2015 ISSN: 2089-1946). 419 - 449

${ }^{25}$ Kemendikbud, Mendidik anak di era digital, 11

${ }^{26}$ Ibid, 18.
} 
kejahatan seperti bullying, pornografi, kekerasan verbal lainnya merupakan akibat dari kegagalan anak menghadapi era diginal ini.

Penawaran penulis adalah multikulturasi Pendidikan Islam sejak dini di dalam keluarga, dengan nilai agama (tauhid) harus terkontruk dengan baik dalam diri anak. Muhammad Nasir dalam "Capita Selekta" mengawali tulisannya dengan memantik sebuah cerita professor yang bunuh diri. Profesor paul Ehrenfest, membunuh anaknya lalu mengahiri hidupnya sendiri, Nasir mengatakan professor itu tidak memiliki pegangan hidup (way of life) yaitu keimanan kepada Allah. ${ }^{27}$ Nasir menyimpulkan bahwa pendidikan harus didasar pada agama. Anak-anak harus mengenal tuhannya dengan sifat-sifatNya. Sifat-sifat Tuhan itulah yang harus dimanivestasi dalam nilainilai multikulturasi pendidikan islam dengan metode pembelajarannya yang telah disebutkan di atas.

\section{Penutup}

Nasehat Al-Ghozali dalam kitab "Ihya' Ulumuddin" tentang pentingnya usia dini menyebutkan bahwa anak itu merupakan amanat bagi kedua orangtuanya, dan hatinya yang bersih merupakan permata mahal, yang masih polos dan belum tersentuh goresan dan lukisan apapun. Masih dapat menerima pahatan apa saja, dan siap mengikuti pengaruh apapun yang disuguhkan kepadanya. Jika anak itu dibiasakan pada hal-hal yang baik dan diajarinya, maka ia akan tumbuh dan berkembang di atas kebaikan tersebut, dan dia akan bahagia di dunia akhirat. Orangtuanya, gurunya dan pengasuhnya akan Bersama-sama memperoleh pahalanaya. Sebaliknya anak tersebut dibiasakan pada hal-hal yang buruk, dan dibiarkan liar seperti binatang, ia akan celaka dan rusak daam hidupnya, dosanya juga akan dipikul oleh orang-orang yang bertanggung jawab dan mengurusinya. ${ }^{28}$

Kegagalan merespon era digital dengan ditandai terjadinya kekerasan anak dalam pendidikan dan di lingkungan masyarakat yang disebut KPAI sebagai akibat dari budaya digital, mengindikasikan gagalnya peran pendidikan sejak dini. Artikel ini menawarkan gagasan secara sederhana akan pentingnya pendidikan Islam dengan pendekatan multikultural. Nilai-nilai multikultural yang dapat diajarkan kepada anak sejak dini adalah seperti humanis, toleransi, menghargai, menerima, mengutamakan

\footnotetext{
${ }^{27}$ Abd. Haris, Pendidikan karakter berbasis Tauhid,...12.

${ }^{28}$ Abu Hamid al-Ghozali, Ihya Ulumiddin, (Beirut: Dar alFikr, t.th) Jilid III. 69-70.
} 
silaturahim, (dialog) pada semua individu, menyayangi kaum lemah, dan monoritas, menjaga persatuan, dan perdamaian, mengembangkan budaya, menjaga kearifan budaya lokal dalam masyarakat. Berbagai macam metode pendidikan anak sejak dini dalam pendidikan Islam, di antaranya adalah: 1. Al-awamiru wa an-nawahy (perintah dan larangan). 2. Taqdimu al-qudwah al-toyyibah (Pendidikan keteladanan). 3. Al-tsawabu wa al-i'qobu (reward and punishment). 4. Al-iyha'u (direct method) atau metode langsung. 5. Metode Qisshoh (bercerita). 


\section{Daftar Pustaka}

A'bbud Abdul Ghina \& Hasan Ibrahim A'dul A'1. 1990. at-Tarbiyah al-Islamiyah wa Tahaddiyat al-Asyr. Mesir: Darul fiqr al-A'roby.

Al-Akhwani, Ahmad Fu'ad at-Tarbiyah fi at-Ta'lim. (Mesir : Darul Ma'arif.

Bank, James A \& Cherry A. McGee Banks. 2010. Multicultural Education: Issues and Perspective. United State of America, Willey.

Haris, Abd. 2012. Pendidikan Karakter Berbasis Tauhid, Sebuah Pendekatan Filosofis Sidoarjo: Afkarpress.

Hasan, Mohammad Tholhah. 2009. Pendidikan Anak Usia Dini dalam Keluarga Jakarta: Mitra Abadi Press.

Hasan, Mohammad Tolhah. 2018. Multiculturalisation of Islamic Education in Indonesia : an Inevitability. international conference on Islam Nusantara, National integrity, and world peace, March, 27-28.

Hashim, Che Noraini \& Hasan Langgulung, "Islamic Religious Curriculum in Muslim Countries: The Experiences of Indonesia and Malaysia" Bulletin of Education \& Research, Vol. 30, No. 1, June 2008.

http://m.suara.com/wawancara. Maria Ulfa : "Kekerasan pada Anak Dimulai dari Internet”, diakses 10 April 2018.

Kemendikbud. 2017. Mendidik Anak di Era Digital. Jakarta: Kemendikbud.

Rahman, Mufiqur. 2017. "Demokrasi dalam Filsafat Pendidikan Barat Dan Islam (Kajian tentang Nilai-Nilai Demokrasi dan Implemntasinya dengan Konteks Pendidikan Indonesia". Cendekia : Vol 3. No. 2. Desember.

Rahman, Mufiqur. 1946. "Menakar Efektivitas Program Aflatoun dalam Pendidikan Karakter”. Jurnal Pendidikan Agama Islam Vol. 3, No. 2, November.

Rosyada, Dede. 2014. "Pendidikan Multikultural Di Indonesia Sebuah Pandangan Konsepsional". Sosio Didaktika: Vol. 1, No. 1.

Tilaar, H.A.R. Multikulturalisme : 2004. Tantangan-Tantangan Besar Masa Depan dalam Tranformasi Pendidikan Nasional. Jakarta : Gramedia.

Wuryanto, AG. "Eka Wenats Digitalisasi masyarakat: Menilik Kekuatan Dan Kelemahan Dinamika Era Informasi Digital dan Masyarakat Informasi”, Jurnal Ilmu Komunikasi, Vol. 1, No.2 Desember 